\title{
Constant Resistance and Yielding Support Technology for Large Deformations of Surrounding Rocks in the Minxian Tunnel
}

\author{
Jinyan Fan $\mathbb{D}^{1,2}$ Zhibiao Guo $\mathbb{D}^{1,},{ }^{1}$ Xiaobing Qiao, ${ }^{3}$ Zhigang Tao $\mathbb{D},{ }^{1}$ and Fengnian Wang $\mathbb{C}^{1,2}$ \\ ${ }^{1}$ State Key Laboratory for Geomechanics and Deep Underground Engineering, Beijing 100083, China \\ ${ }^{2}$ School of Mechanics and Civil Engineering, China University of Mining and Technology (Beijing), Beijing 100083, China \\ ${ }^{3}$ Gansu Changda Highway Co., Ltd, Lanzhou 730000, China \\ Correspondence should be addressed to Zhibiao Guo; guozhibiaobj@126.com and Zhigang Tao; taozhigang@263.net
}

Received 25 March 2020; Revised 30 July 2020; Accepted 4 September 2020; Published 28 September 2020

Academic Editor: Chunshun Zhang

Copyright (C) 2020 Jinyan Fan et al. This is an open access article distributed under the Creative Commons Attribution License, which permits unrestricted use, distribution, and reproduction in any medium, provided the original work is properly cited.

During the excavation of the Minxian tunnel, problems of large deformations of surrounding rocks and failure of support structures appeared frequently, which caused serious influences on construction safety and costs of the tunnel. Based on laboratory analysis of mineral composition and field investigations on deformation characteristics of the surrounding rocks, the large deformation mechanism of surrounding rocks of the tunnel was considered as water-absorbing swelling molecules of carbonaceous slate and stress-induced asymmetric structural deformations of the surrounding rocks. The structural deformations of surrounding rocks mainly include bending deformation, interlayer sliding, and crushing failure of local rock blocks. Then, a new constant resistance and yielding support technology based on the constant resistance and large deformation (CRLD) anchor cable was proposed to control large deformations of surrounding rocks. The field tests and deformation monitoring were carried out. The monitoring results showed that compared with original support measure, the surrounding rock deformations, stresses of primary supports, and permanent lining using new support technology decreased greatly. Among them, the maximum deformation of surrounding rock was only $73 \mathrm{~mm}$. The effects of field application and results of deformation monitoring showed that the new support technology can effectively control large deformations of the surrounding rocks in the Minxian tunnel.

\section{Introduction}

In recent years, with the economic development of western China, transportation networks including railway and expressway have been developed rapidly. In order to shorten the transportation distance, there are more and more mountain tunnels due to high altitude and mountainous landform [1-5]. Among them, large deformation of the surrounding rock caused by high in situ stress, weak rock, and poor geological condition is one of the critical and challenging problems, which has serious influence on tunnel construction and stability [6-8]. In case of large deformation cannot be effectively controlled during the construction, the decrease of tunnel section, cracking of shotcrete, failure of support structures, and collapse of surrounding rocks will occur easily.
Many studies have been conducted to investigate the control technologies of large deformation of surrounding rock in soft rock tunnels. In order to prevent the large convergences of surrounding rocks in a complex fault zone of the Enasan Tunnel in Japan, Kimura et al. [9] presented a flexible support system consisting of steel pipes forepoling, quickly spraying concrete, steel ribs with sliding sets, steel fibre-reinforced concrete, rock bolts with lengths of $9 \mathrm{~m}$ and $13.5 \mathrm{~m}$, allowable radial displacement $(30-50 \mathrm{~cm})$, and secondary concrete lining in combination. Zhang and Bai [10] described the control countermeasures for large deformations of the first squeezing tunnel in China, the Jiazhuqing tunnel. Based on the principles of release-restriction combination, a combined support method of long rock bolts + retractable U-type steel frame + double-layered sprayed concrete + bigger allowable deformation + higher 
stiffness concrete lining was conducted, and the effective control result was obtained. Hoek and Guevara [11] introduced the extreme squeezing deformation problems encountered during the construction of the Yacambu-Quibor tunnel that was excavated in silicified and graphitic phyllites at depths of up to $1270 \mathrm{~m}$ below surface under the Andes. The cross section of the tunnel was filled with squeezing rock completely at the sections of maximum deformation. In order to restrict the large squeezing deformation of surrounding rock, a yielding support using steel set with joint gaps was presented, and the good control effect was obtained. Zhang et al. [12] provided comprehensive technical measures including higher support stiffness, double-layered primary support, strengthening of presupport, and increase of preset deformation, and grouting reinforcement for large deformations of the tunnel excavated in weak rocks under high in situ stresses used numerical calculations and field experiments. Ding et al. [13] described the large deformation of two parallel diversion tunnels excavated in ultrathin-layered weak rocks. The deformation behavior and stress distribution characteristics of the surrounding rock masses under original support measures were studied by methods of field monitoring and numerical simulation. And the high prestressed long cables were proposed and tested as effective reinforcement support measures to ensure the tunnel stability. Cao et al. [14] studied the deformation characteristics and control technology of the Laodongshan tunnel where large deformation and failure of primary support occurred during the tunnel excavation. They found that for tunnels constructed in weak rock mass under high in situ stress, the controlling principle of tunnel deformation ought to be based on the combination of stress releasing and support resistance. And a combined support countermeasure including grouting reinforcement, steel tubes advanced support, shaped steel frame, doublelayer steel meshes, and secondary lining was proposed and applied successfully in the tunnel.

It can be seen from the cases above that the combination of flexible and rigid supports is unified control principle for large deformation problem of the tunnel in the world. That is, flexible support is firstly adopted to release deformation energy of the surrounding rock, and rigid support is then installed to restrict further deformation of surrounding rock. Good results have been obtained by using different control technologies in many tunnels with problems of large deformations of surrounding rocks under this control principle. However, there are still some problems that can be further improved in application of the existing support systems. For example, the existing flexible support technologies (e.g., retractable steel frame, yielding steel sets, or steel fibre concrete) always have high deformation stiffness but small strength so that the supports will not apply sufficient resistance on surrounding rock when they deform with surrounding rock synchronously, which will lead to that deformation of surrounding rock being prone to exceeding the allowable value. On the contrary, the existing rigid support technologies (e.g., traditional rock bolt, heavy steel frame, or sprayed concrete) have high strength but small deformation stiffness, which will lead to failure of the supports when the deformation of surrounding rock is bigger than the allowable value. Moreover, both flexible and rigid supports are usually constructed separately in the field, which reduces effect of their combination. Thus, techniques for controlling large deformation of the soft rock tunnel require further development.

In this paper, the Minxian tunnel was presented as a case study to introduce a new control measure for large deformation of soft rock tunnels. Firstly, the deformation characteristics of surrounding rocks using the original support method were summarized in field. Then, the deformation mechanism of surrounding rock of the tunnel was analyzed through laboratory analysis and field investigation. Moreover, a new constant resistance and yielding support technology was proposed and tested on-site. And the first application of energy-absorbing cable with characteristics of constant resistance and large deformation (CRLD) on the control of large deformation of the soft rock tunnel is of particular interest. Finally, the monitoring results show that the large deformation of surrounding rock was effectively controlled by this new support method. This successful case may be a valuable reference for similar tunnels in the future.

\section{Project Overview}

2.1. Tunnel Profile. The Minxian tunnel is located in Min county of Dingxi city in Gansu province, China, and it is an important control engineering of the G75 (Lanzhou-Haikou) expressway (Figure 1(a)). The tunnel is a $2800 \mathrm{~m}$-long separated twin-tube mountain tunnel (Figure 1(b)). The distance between left and right sides of the tunnel is a minimum of $28 \mathrm{~m}$ around the entrance and exit, and other positions are all over $50 \mathrm{~m}$ (Figure 1(c)). The maximum overburden depth of the tunnel is $287 \mathrm{~m}$, and the area of cross section is about $110 \mathrm{~m}^{2}$. The blasting technique and mechanical breaking were used for the excavation of the tunnel. The three-step method with $4.8 \mathrm{~m}$ in length along longitudinal direction was adopted as the layout of the tunnel face.

2.2. Geological Conditions. Intense folding and tectonic motions in geological history resulted in complex regional structures in the project area. Under the effects of region dynamics, there are two large reverse faults (F2 and F24) filled with breccia, fault gouge, and crushed rock along the tunnel heading direction (Figure 2). The occurrence of F2 is $\mathrm{NE} 47^{\circ} \angle 60^{\circ}$, and the width of the fracture zone is about $360 \mathrm{~m}$; F24 is NE $43^{\circ} \angle 76^{\circ}$ and about $200 \mathrm{~m}$. There were still some small faults during the excavation, which caused the angular unconformity of the layered slate and led to asymmetric deformation of the tunnel.

The surrounding rock of the tunnel is mainly dominated by Permian carbonaceous slate with scattered distribution of intercalated siltstone (Figure 2). The carbonaceous slate is strongly or medium weathered and a kind of slightly metamorphic rock with developed foliations (Figure 3). Thickness of single carbonaceous slate layer is about $2-5 \mathrm{~cm}$. The rock mass of the tunnel is greatly fragmented under 


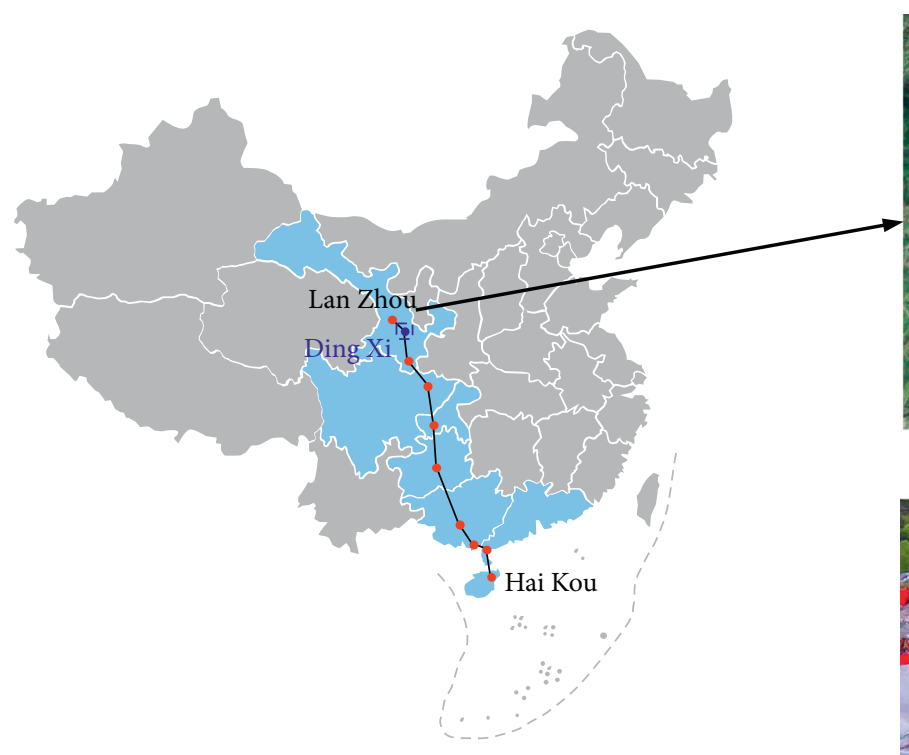

(a)

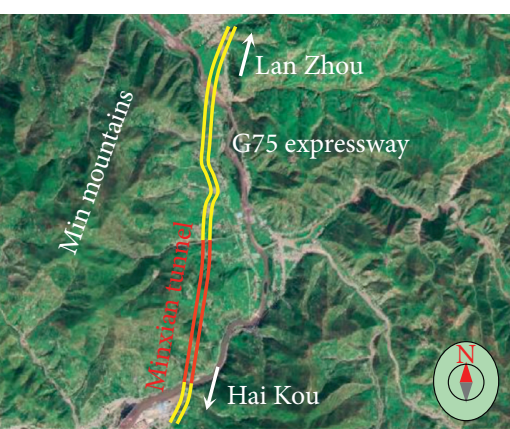

(b)

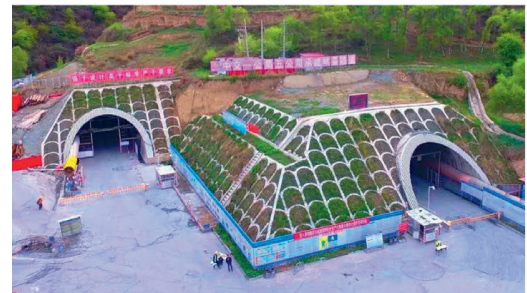

(c)

Figure 1: Profile of the Minxian tunnel. (a) G75 (Lanzhou-Haikou) expressway in China. (b) Topographic map of the Minxian tunnel. (c) Picture of the tunnel entrance.

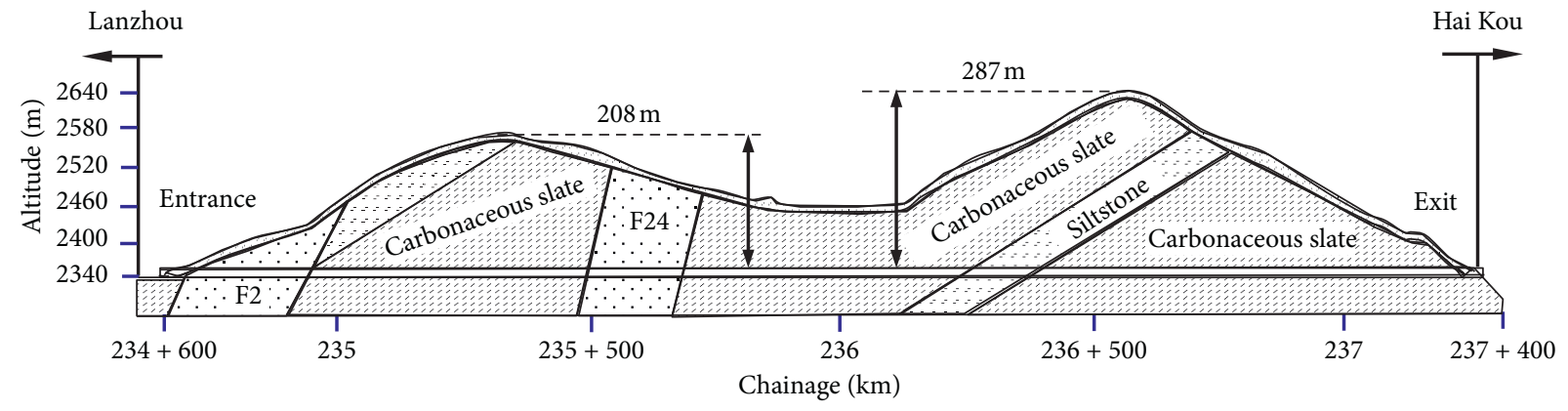

FIGURE 2: Longitudinal profile of the Minxian tunnel.
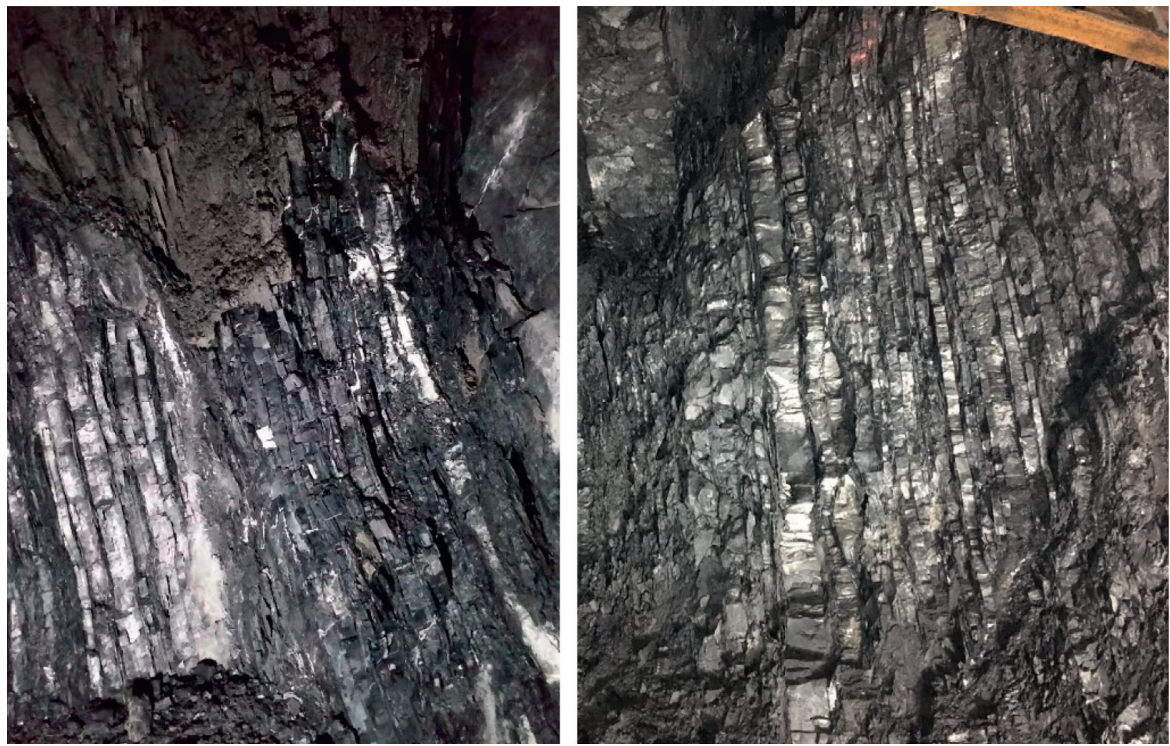

FIGURE 3: Strongly weathered carbonaceous slate exposed by the tunnel face. 
influences of developed foliations and joints (Figure 3). According to the Standard for Engineering Classification of Rock Mass, the surrounding rocks of the tunnel are classified in grade $\mathrm{V}$, the worst rock mass quality.

The mechanical properties of the carbonaceous slate with different dip angles of the foliation are presented in Table 1. It can be seen that the dip angle of foliation has important influences on the mechanical properties of carbonaceous slate. When the angles between the foliation and load are $0^{\circ}$ and $90^{\circ}$, UCS values of the carbonaceous slate are about $36 \mathrm{MPa}$. However, UCS reduces to $2.19 \mathrm{MPa}$ when the angle is $60^{\circ}$. The anisotropic mechanical properties of carbonaceous slate make the failure mechanism of the tunnel complicated.

In order to understand the mineral composition of carbonaceous slate, XRD analysis was carried out. Results indicate that carbonaceous slate is composed of siliceous, argillaceous, iron-carbonaceous minerals and terrigenous clasts, and their relative content in five samples is presented in Table 2. It can be seen that main minerals of carbonaceous slate in the Minxian tunnel are quartz, illite, chlorite, and ankerite; and their relative proportions are in the range of $35.2-85 \%, \quad 6.16-36.72 \%, \quad 5.7-21.42 \%$, and $0-14.4 \%$, respectively.

The hydraulic fracturing method was adopted to measure in situ stresses of the tunnel by the project department. The minimum horizontal principal stress $\sigma_{3}$ was $3.45 \mathrm{MPa}$, and orientation was $\mathrm{S} 43^{\circ} \mathrm{E}$. The maximum horizontal principal stress $\sigma_{1}$ was $5.56 \mathrm{MPa}$, and orientation was $\mathrm{N} 47^{\circ} \mathrm{E}$; the angle between $\sigma_{1}$ and the axial direction of the tunnel was $30-50^{\circ}$. The middle principal stress $\sigma_{2}$ was $4.27 \mathrm{MPa}$, which was approximately equal to the gravity caused by overlying rock mass of the tunnel. The lateral stress coefficient defined as $\sigma_{1} / \sigma_{2}$ is 1.3 , and the ratio of $\sigma_{3} / \sigma_{1}$ is 0.62 . The bedrock fissure water is the main source of groundwater in the tunnel, and its content is very low. There is little rainfall in dry season and temporary settlement of rainwater in rainy season, which all have few impacts on the tunnel.

According to investigations and tests, the geological characteristics of the Minxian tunnel are summarized as shallow buried depth, low in situ stress, simple hydrological conditions, and no risk of water inrush. However, the geological characteristics also contain swelling clay minerals, developed foliations and joints in surrounding rocks, changeable occurrences of strata affected by regional geological movements, and that the surrounding rocks are weathered easily and broken after being exposed.

\section{Problems Encountered during Excavation}

3.1. Original Support Measures. The cross section shape of the tunnel is a three-centered arch. The design width and height are $12 \mathrm{~m}$ and $10 \mathrm{~m}$, respectively. Composite support technologies were used for the surrounding rock support of the tunnel (Figure 4). The primary supports included heavy HW175 steel frames $(40.3 \mathrm{~kg} / \mathrm{m})$ at $0.6 \mathrm{~m}$ spacing along the longitudinal axis, steel mesh with the diameter of $8 \mathrm{~mm}$ steel, $26 \mathrm{~cm}$ thickness of C25 sprayed concrete, ordinary rock bolts with $25 \mathrm{~mm}$ in diameter, $3.5 \mathrm{~m}$ in length, and interval $1.0 \mathrm{~m} \times 1.0 \mathrm{~m}$. In addition, feet-lock anchor pipes with the diameter of $89 \mathrm{~mm}$ and length of $3.5 \mathrm{~m}$ at the bottom of steel arch were used to control subsidence of the steel frames. The $60 \mathrm{~cm}$-thick reinforced concrete lining was adopted as the permanent support, which was carried out after the surface displacements of surrounding rocks being stable or when the distance from the tunnel face would reach $70 \mathrm{~m}$.

3.2. Large Deformations of Surrounding Rocks. When the tunnel was excavated through the fault zone or the heading face approached the maximum buried depth of the tunnel, the deformation of surrounding rock mass increased greatly and continuously. In the mileage range of $235+478 \sim 235+482$ kilometres of the right tunnel, the maximum deformation of surrounding rock appeared at waist, and the cumulative value reached $300 \mathrm{~mm}$ during seven days. With the deformation increasing, the sprayed concrete began to crack and steel frames deformed gradually. Two months later, the maximum crown settlement and deformation of sidewall reached $400 \mathrm{~mm}$ and $1200 \mathrm{~mm}$, respectively (Figure 5). Then, the failed primary supports had to be removed and replaced.

As can be seen from field surveys, the evolution process of surrounding rock deformations and failure of support structures could be divided into six stages (Figure 6): (1) partial collapse of the tunnel face, (2) local deformation of surrounding rock, (3) cracking and falling off of sprayed concrete, (4) distortion of steel frames, (5) large-area failure of shotcrete, and (6) secondary lining cracking.

3.3. Influences on Tunnel Construction. The construction of the tunnel began in March 2016. The advancing distance is $1.2 \mathrm{~m}$ in each cycle. When rock mass was hard or unbroken, blasting would be used for the excavation, while jackdrill is used for soft or broken rock mass. From March 2016 to March 2018, the total excavated length was $813 \mathrm{~m}$ in the left tunnel. The average velocity was $1.08 \mathrm{~m} / \mathrm{d}$ during 25 months. However, since the working face approached the fault zone, original support system could not control continuous deformations of surrounding rocks, and failure of primary supports occurred frequently. The replacement ratio of steel frame reached $46 \%$ during this period. A total length of $72 \mathrm{~m}$ was advanced from April to November 2018. The average velocity was $0.3 \mathrm{~m} / \mathrm{d}$ during eight months, which slowed progress of the project seriously and increased cost greatly. Moreover, there were a wide range of cracks gradually on the secondary lining (Figure $7(\mathrm{a})$ ) due to failure of primary supports and the sustained deformation of the surrounding rock. In order to replace the cracked secondary lining located in the mileage range of $235+442 \sim 235+480 \mathrm{~km}$ (Figure $7(\mathrm{c})$ ), the temporary reinforcement support using steel frame was installed (Figure 7(b)) and the heading face of the left tunnel had to be shut down in December 2018. The total cost of reconstruction of $38 \mathrm{~m}$ length reached $\$ 1.7$ million. 
TABLE 1: Mechanical properties of the carbonaceous slate.

\begin{tabular}{ccccccc}
\hline & $\theta\left(^{\circ}\right)$ & UCS $(\mathrm{MPa})$ & $\sigma_{\mathrm{t}}(\mathrm{MPa})$ & $\mathrm{C}(\mathrm{MPa})$ & $\mathrm{E}(\mathrm{GPa})$ & $\mu$ \\
\hline \multirow{3}{*}{ Carbonaceous slate } & 0 & 35.74 & 3.25 & 4.17 & 0.54 & 0.16 \\
& 60 & 2.19 & 0.15 & 0.20 & 2.40 & - \\
& 90 & 36.53 & 1.22 & 2.04 & 0.15 \\
\hline
\end{tabular}

TABle 2: Mineral composition and relative content of carbonaceous slate.

\begin{tabular}{|c|c|c|c|c|c|c|c|c|}
\hline \multirow{2}{*}{ No. } & \multicolumn{8}{|c|}{ Relative mineral content (\%) } \\
\hline & Quartz & Illite & Chlorite & Ankerite & Kaolinite & Potassium feldspar & Siderite & Halite \\
\hline $1 / 5$ & 59.6 & 27.32 & 9.9 & & 2.38 & & & 0.9 \\
\hline $2 / 5$ & 35.2 & 36.72 & 21.42 & & 3.06 & 2.2 & & 1.4 \\
\hline $3 / 5$ & 65.2 & 12.28 & 6.32 & 14.4 & & & 1.1 & 0.8 \\
\hline $4 / 5$ & 71.6 & 6.16 & 16.64 & 4.6 & & & & 0.9 \\
\hline $5 / 5$ & 85 & 9.3 & 5.7 & & & & & \\
\hline
\end{tabular}

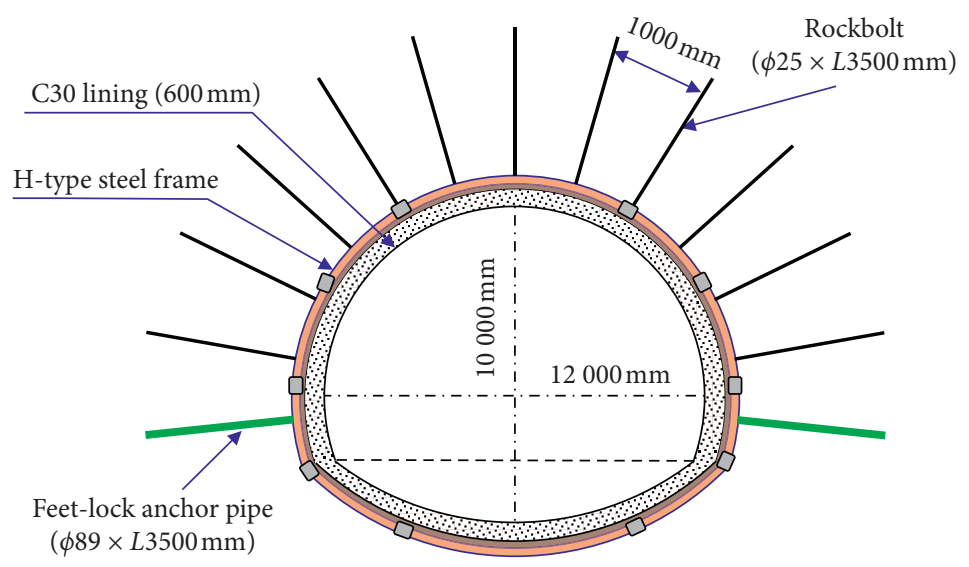

Figure 4: Original support measures.

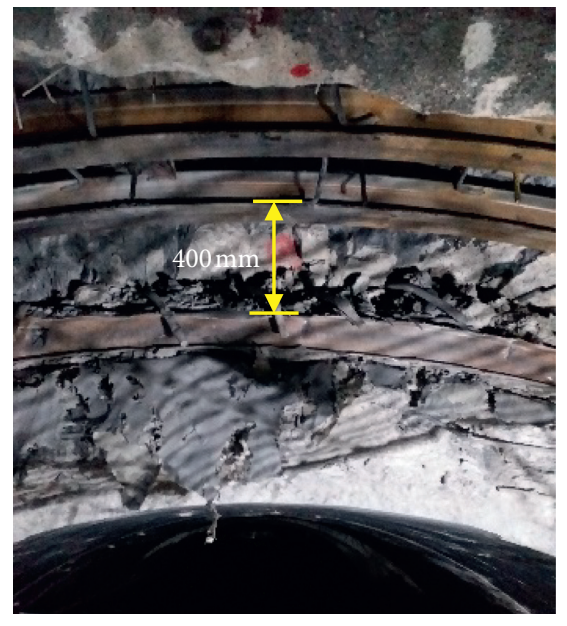

(a)

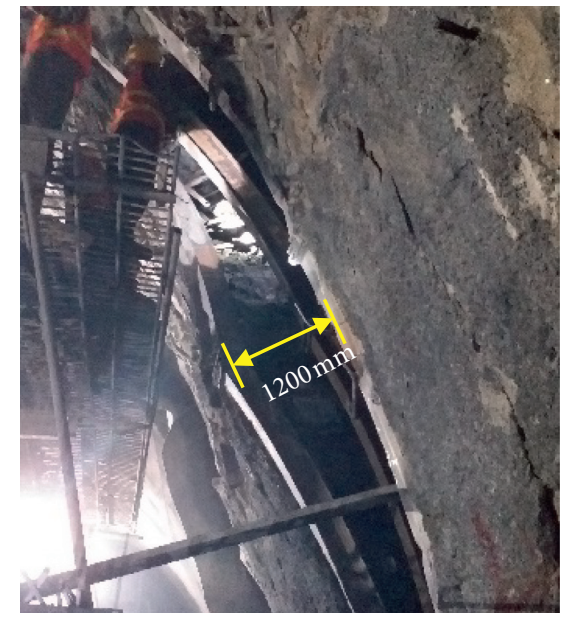

(b)

FIGURE 5: Large deformations of surrounding rocks. (a) Crown settlement. (b) Large deformation of surrounding rock at left shoulder. 


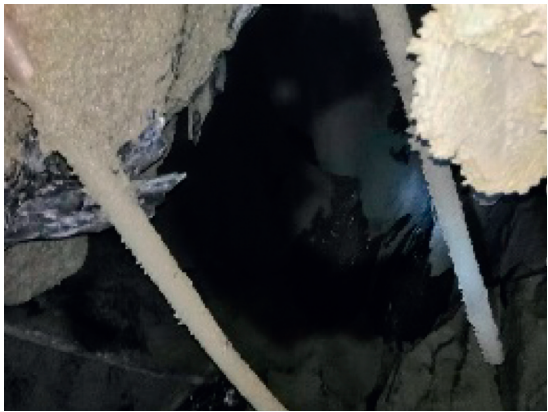

(a)

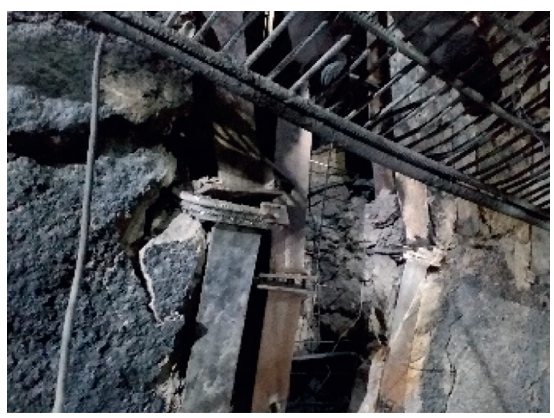

(d)

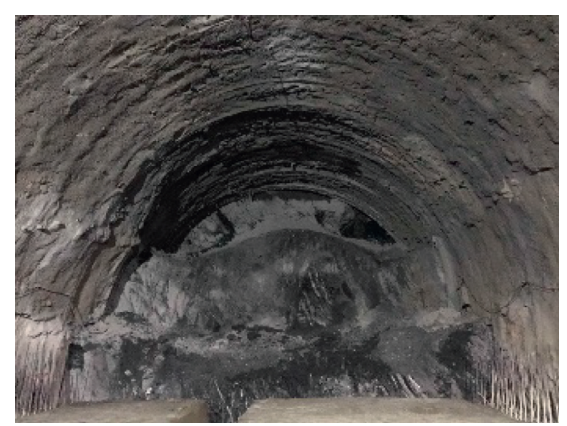

(b)

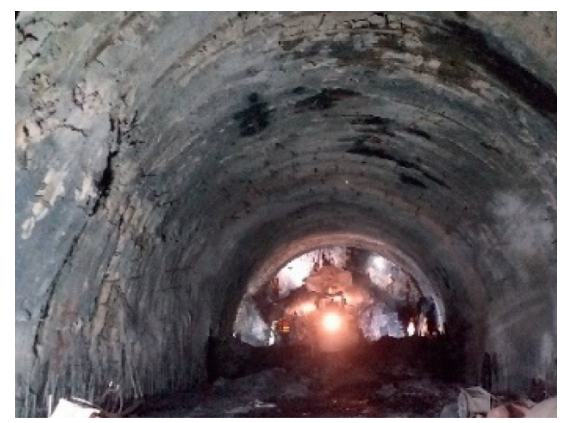

(e)

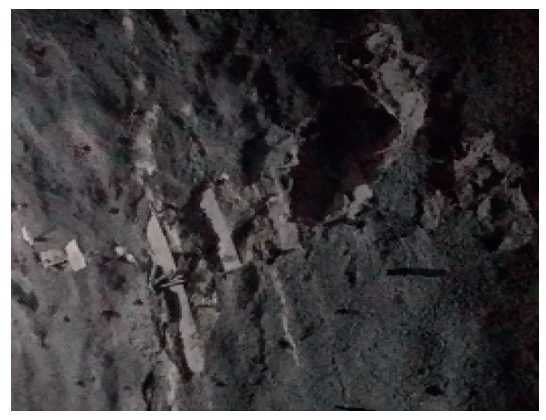

(c)

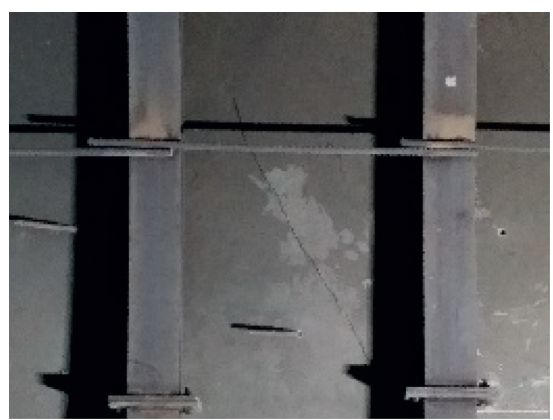

(f)

Figure 6: Failure process of the tunnel support system. (a) Tunneling face collapse. (b) Local deformation. (c) Cracking and falling off of sprayed concrete. (d) Distortion of steel frame. (e) Large-area failure of sprayed concrete. (f) Secondary lining cracking.

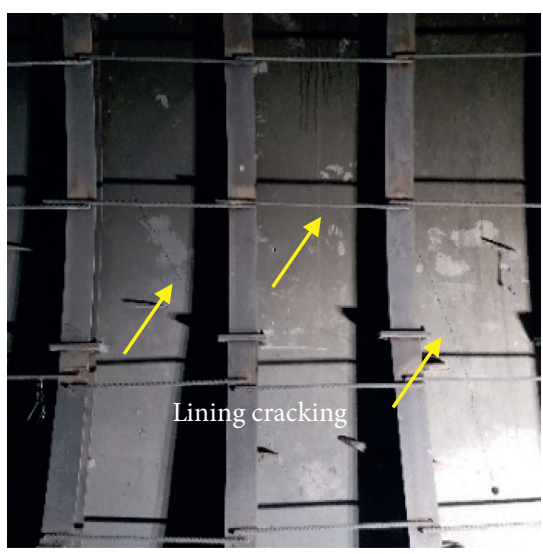

(a)

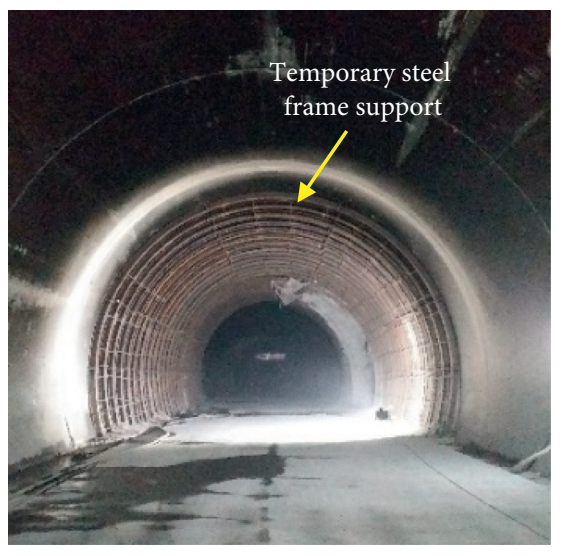

(b)

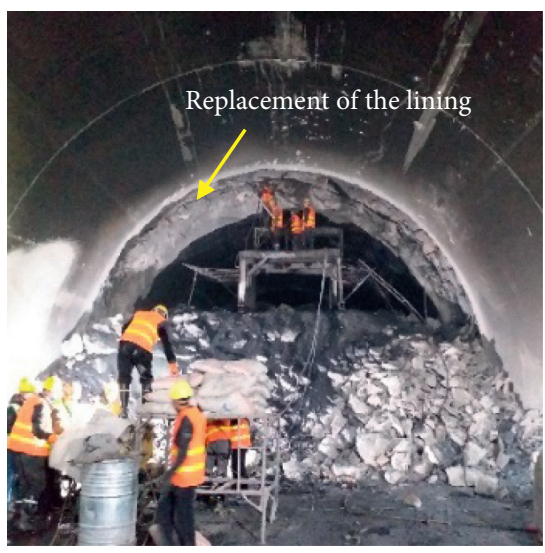

(c)

FIGURE 7: Failure and replacement of permanent lining in the left tunnel. (a) Cracking of the lining. (b) Temporary steel frame reinforcement support. (c) Reconstruction of the lining.

\section{Key Techniques of Constant Resistance and Yielding Support}

4.1. Deformation Mechanism of the Surrounding Rock. According to results of XRD analysis, there is a certain amount of illite in the mineral composition of the carbonaceous slate. Illite is a kind of swelling mineral, and the mechanism is that crystal cells with certain distances are prone to increasing the volume of crystals by absorbing water molecules [15]. The exposed surrounding rocks to such mineral are usually easy to be weathered, softened, and fissured.
As mentioned in Section 2.2, when the heading face approached drainage divide of the mountain, the deformation of surrounding rock increased greatly. According to field investigation and statistics, when overburden thickness of the tunnel was less than $200 \mathrm{~m}$, average deformation of surrounding rock is $400 \mathrm{~mm}$, and the maximum deformation value is $850 \mathrm{~mm}$. However, when the overburden thickness is greater than $200 \mathrm{~m}$, the average deformation is $750 \mathrm{~mm}$, and the maximum deformation value is $1200 \mathrm{~mm}$. The results indicate that deformation degree of surrounding rock is related to the buried depth. Moreover, the 
deformation of surrounding rock has significant asymmetry. There are different deformation values at both sides of the tunnel, even at different positions around the cross section (e.g., vault, shoulders, sidewalls, or arc feet) due to highly developed weak structure surfaces and foliations. As shown in Figure 8, there are mainly three structural failure types in the Minxian tunnel: (1) The thin rock slabs of carbonaceous slate are bent under the radial concentrated stress when the normal direction of the rock slabs is in line with the radial direction of the tunnel. (2) When the normal direction of strata is perpendicular to the radial direction of the tunnel, interlayer sliding occurs under the radial concentrated stress due to the smooth bedding surface. (3) Crushing failure of local rock blocks and key positions around the tunnel happens under uneven and high circumferential concentrated stress, which causes lumps off-falling or collapse of the tunnel face.

To sum up, the large deformation mechanism of surrounding rock of the Minxian tunnel can be determined as water-absorbing swelling molecules of soft rock and stressinduced asymmetric structural deformation of surrounding rock.

4.2. Control Principles. Referring to the current research results for large deformation of the soft rock tunnel in the world and aiming at the deformation mechanism of surrounding rock in the Minxian tunnel, the control principles of new support measures are present as follows: (1) In order to prevent local unstable positions on surface of surrounding rock from lumps off-falling and collapsing and the exposed rock mass from water-absorbing swelling and weathering, the exposed surface of surrounding rock should be closed in time. (2) In order to utilize the selfsustaining capacity of surrounding rock as much as possible, the integrity, stiffness, and strength of jointed rock mass should be improved. (3) In order to reduce loads acting on support system, the accumulated deformation energy in the surrounding rock should be released moderately. (4) In order to limit continuous deformation of surrounding rock, the working resistance of the support system should be increased.

4.3. Constant Resistance and Large Deformation (CRLD) Anchor Cable. As mentioned in Introduction, the current flexible support technologies always have high deformation stiffness but small support strength. However, the rigid support technologies have high strength but small deformation stiffness, and both flexible and rigid supports are usually constructed separately, which reduces effect of their combination. In order to combine the yielding and rigid characteristics together better, He et al. [16] developed a novel energy-absorbing bolt (cable) possessing ultrahigh energy-absorbing capacity and high constant resistance, namely, "He bolt" or "constant resistance and large deformation (CRLD) anchor cable."

Figure 9 shows the structure diagram of the CRLD cable (Figure 9(a)) and the real product picture (Figure 9(b)). It consists of a stranded steel wire, a lockset device, a steel tray,

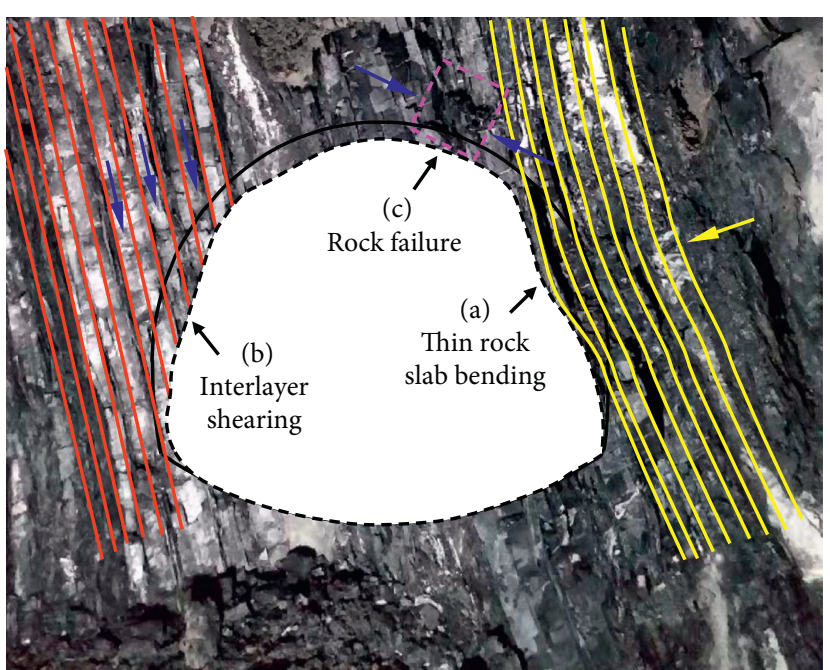

FIGURE 8: Three failure types of surrounding rocks in the tunnel. (a) Thin rock slab bending. (b) Interlayer shearing. (c) Local failure of rock blocks.

and a constant resistance body including a piston-like cone installed on the stranded steel wire and a sleeve pipe with its inner diameter slightly smaller than the diameter of the large-end diameter of the cone.

The working principle of the CRLD anchor cable is shown in Figure 10. When the external load caused by the surrounding rock deformation is smaller than working resistance of CRLD anchor cable, the tunnel is stable and the steel wire gives rise to elastic deformation. With the increase of surrounding rock deformation, the external load will be equal to working resistance of the CRLD anchor cable that is dependent on the elastic property of the sleeve pipe, structure of the cone body, and friction properties of the interface between the cone and sleeve pipe. Then the sleeve pipe will slip along the movement direction of surrounding rock deformation. The slippage of sleeve pipe is actually the process of energy releasing of surrounding rock and elongation and energy absorbing of the CRLD anchor cable. During the process of slippage, the working resistance of the CRLD anchor cable remains constant. It is noted that the working resistance of the CRLD anchor cable (i.e., threshold of constant resistance body sliding) is smaller than elastic limit of the stranded steel wire, which makes only the steel wire to deform elastically under the external load.

4.4. Key Techniques. The improved combined support method based on the CRLD anchor cables was proposed to control large deformation of the surrounding rock in the Minxian tunnel. Four arrangement designs including different steel types and anchor cable spacing were preliminarily identified and conducted in field, respectively. According to the field testing results, an optimal support scheme was determined. The section layout of the selected support technology is shown in Figure 11, and the details are described as follows. 


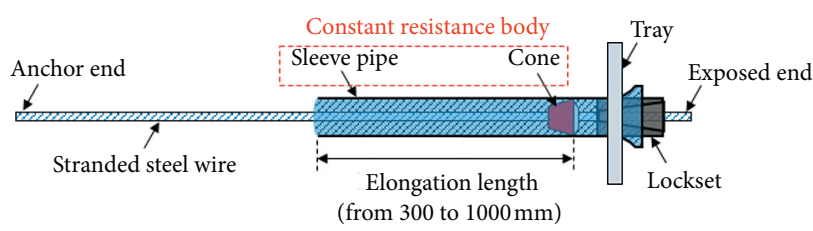

(a)

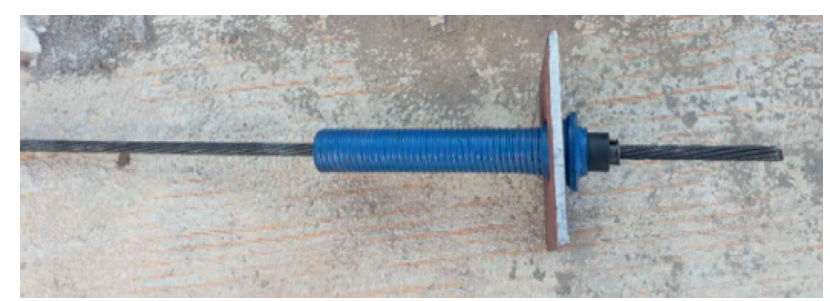

(b)

FIgURe 9: CRLD anchor cable. (a) Structure diagram. (b) Real product picture.

4.4.1. Advanced Support. In view of the jointed rock mass, in order to prevent the collapse of rock mass around the tunnel face, the front canopy using the steel pipe was adopted as the advanced support with $3.0 \mathrm{~m}$ in length, $42 \mathrm{~mm}$ in diameter, a ring spacing of $0.3 \mathrm{~m}$, and a longitudinal pitch of $1.2 \mathrm{~m}$.

4.4.2. Quickly Spraying Concrete. According to the control principle (1) mentioned in Section 4.2, $30 \mathrm{~mm}$-thick shotcrete was sprayed immediately on surface of exposed surrounding rock mass after the cross section of the tunnel being excavated (Figure 12(b)), which could improve the stabilization of rock blocks on surface of surrounding rock and effectively prevent weathering of exposed rock mass.

4.4.3. Short CRLD Anchor Cable. Under the influence of excavation unloading and stress concentration, the rock mass around the tunnel is more broken, and the bearing capacity reduces greatly. In order to understand state of the surrounding rock, the acoustic testing method was used to examine the range of excavation disturbance [17]. The distance between two testing points is $0.5 \mathrm{~m}$, and the maximum testing depth of each borehole is $30 \mathrm{~m}$. A typical test result is shown in Figure 13. It can be seen that the acoustic velocity fluctuates greatly in the range of $1000 \mathrm{~m} / \mathrm{s}$ to $3000 \mathrm{~m} / \mathrm{s}$, which indicates that the surrounding rock has a high degree of nonuniformity and breakage. According to the obtained cores and acoustic test results, the surrounding rock can be divided into four zones: (1) concrete lining, from surface to $1.5 \mathrm{~m}$, has an average acoustic velocity of $1500 \mathrm{~m} / \mathrm{s}$; (2) fractured zone, from $1.5 \mathrm{~m}$ to $4 \mathrm{~m}$, has an average acoustic velocity of $1185 \mathrm{~m} / \mathrm{s}$; (3) plastic zone, from $4 \mathrm{~m}$ to $10 \mathrm{~m}$, has an average acoustic velocity of $1586 \mathrm{~m} / \mathrm{s}$; and (4) undisturbed zone (deeper than $10 \mathrm{~m}$ ) has an average acoustic velocity of $1808 \mathrm{~m} / \mathrm{s}$.

According to control principle (2), short CRLD anchor cables with $7.0 \mathrm{~m}$ in length, $1.2 \mathrm{~m}$ in longitudinal spacing, and $1.0 \mathrm{~m}$ in circumferential spacing were installed immediately on the designed cross section after the previous shotcrete being finished (Figure $12(\mathrm{~b})$ ). The $300 \mathrm{kN}$ pretightening force was applied to impose the initial constraints on the surrounding rock. On the one hand, the short CRLD cables can anchor several thin rock slabs together to form thick composite slab, which will improve the bending stiffness of the shallow surrounding rock greatly. On the other hand, the combination of short CRLD cables can form a bearing arc zone around the cross section of the tunnel,

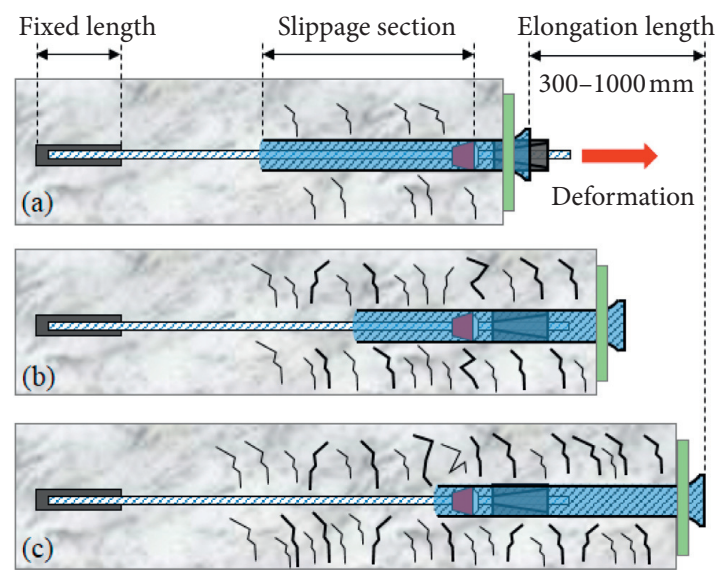

Figure 10: Working principle of the CRLD anchor cable. (a) Pretightening state. (b) Working state. (c) Ultimate state.

which will increase the self-bearing capacity of the shallow surrounding rock significantly.

4.4.4. Long CRLD Anchor Cable. According to the acoustic test results, the range of excavation disturbance zone can be considered to be within $10 \mathrm{~m}$ from the surface of the surrounding rock. In order to control the stability of surrounding rock within the relaxation zone, the strength of rock mass in deep stable zone must be mobilized. Thus, long CRLD anchor cables with $12.3 \mathrm{~m}$ length, $1.2 \mathrm{~m}$ longitudinal spacing, and $2.0 \mathrm{~m}$ circumferential spacing were constructed on the next cross section with $0.6 \mathrm{~m}$ spacing along tunneling direction (Figure 12(b)). The pretightening force was also $300 \mathrm{kN}$. Meanwhile, several reinforced long CRLD anchor cables were installed on left or right shoulder of the first step according to the dip direction of the surrounding rocks to improve the deformation stiffness of key positions. The group of long CRLD anchor cables can not only absorb the deformation energy of rock mass and release the stress of surrounding rock through slippage of sleeve pipe, but also apply constant resistance to the surrounding rock to limit its continuous deformation at the same time.

4.4.5. Preset Deformation and Double-Layered Rigid Supports. According to the control principle (3), in order to release deformation energy of surrounding rock, an appropriate amount of deformation should be allowed. The 


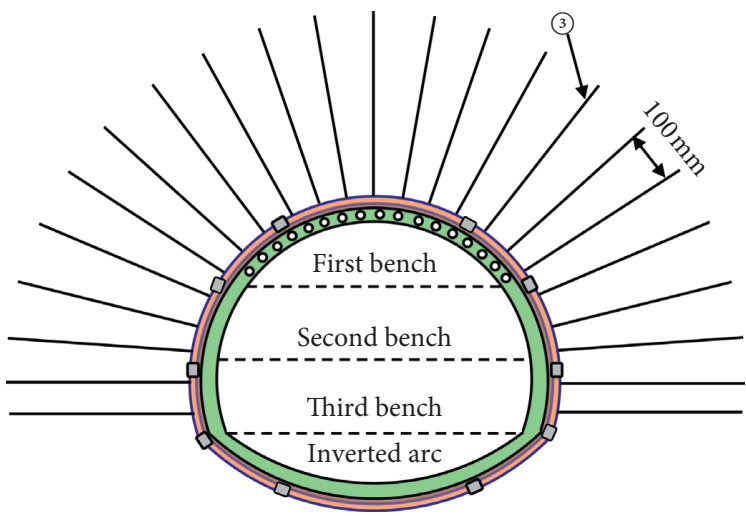

(a)

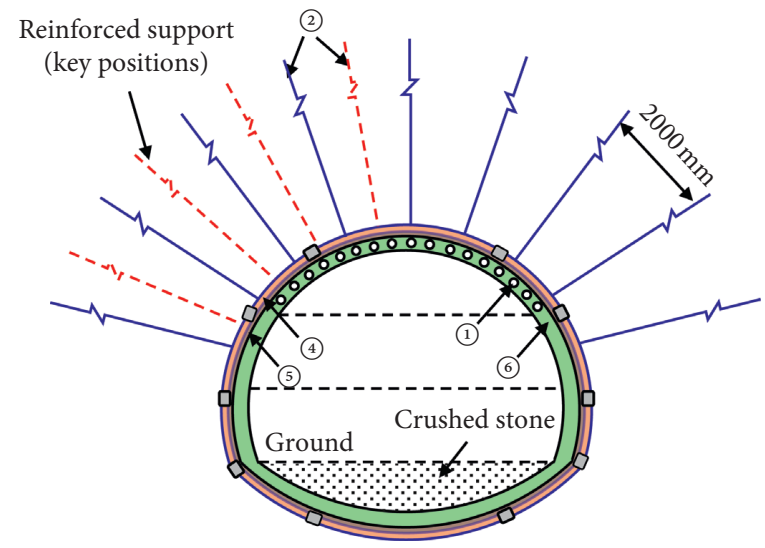

(b)

FIGURE 11: The new constant resistance and yielding support technology. (a) First section. (b) Second section.

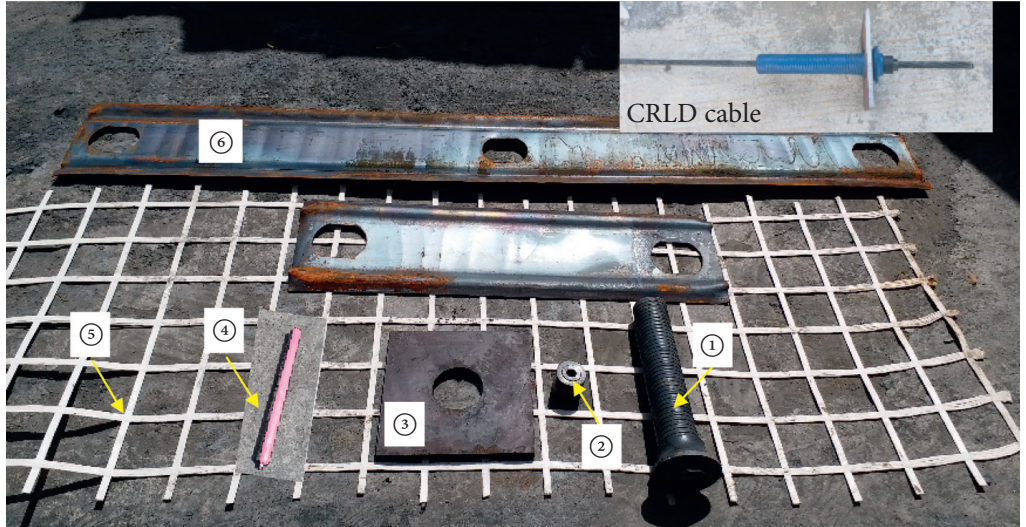

(a)

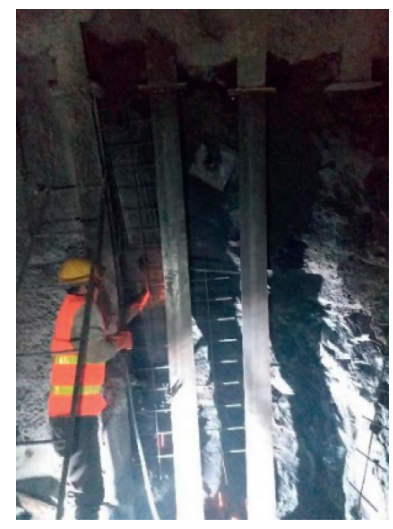

(c)

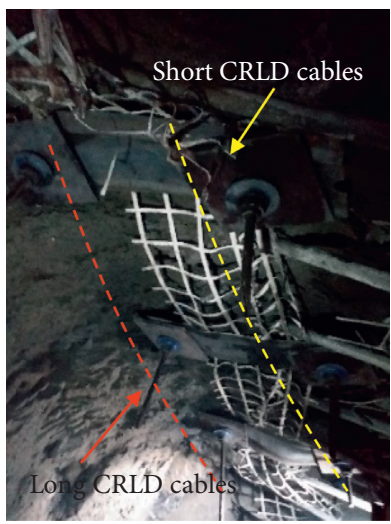

(b)

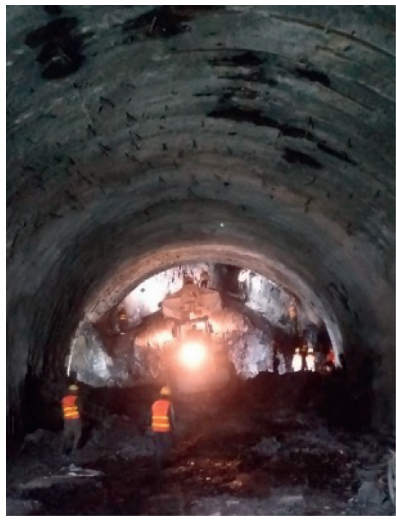

(d)

FIGURE 12: Field construction pictures of the new support technology. (a) Outfit of CRLD cable system. (b) Finished CRLD anchor cables. (c) I20 steel frames. (d) Sprayed concrete with a thickness of $26 \mathrm{~cm}$.

preset deformation between surrounding rock and next rigid support was $20-30 \mathrm{~cm}$.

According to the control principle (4), the passive rigid support should be used to provide higher support strength. The double-layered rigid supports were then constructed. The I20a steel frame was adopted as the first layer rigid support with $0.6 \mathrm{~m}$ spacing (Figure 12(c)). $26 \mathrm{~cm}$-thick shotcrete was used as the second layer of the rigid support, and the field effect after spraying is shown in Figure 12(d). 


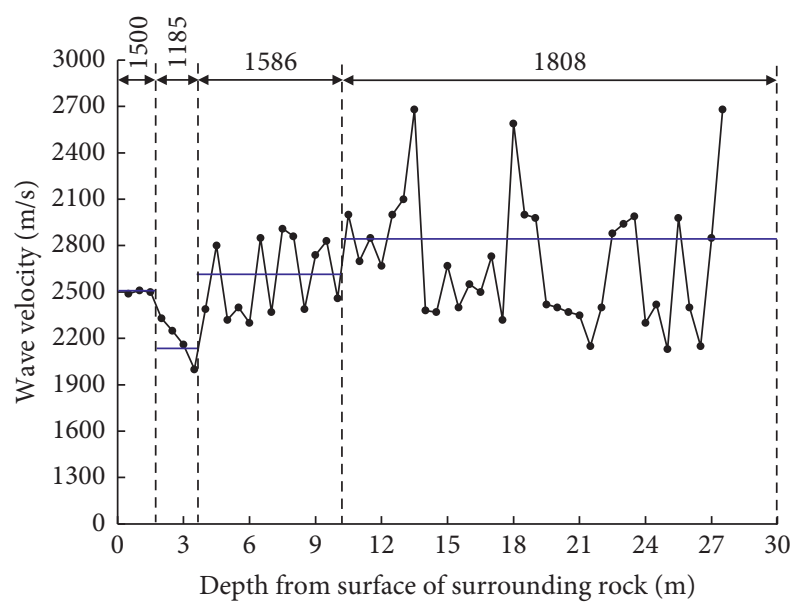

FIgUre 13: Acoustic wave testing result.

4.4.6. Permanent Lining. The permanent lining should be constructed once the convergence deformation of surrounding rock tended to be stable. The waterproof cloth was installed, and $50 \mathrm{~cm}$-thick steel reinforced concrete lining was then casted (Figure 14).

\section{Monitoring of Deformations and Stresses}

5.1. Monitoring Scheme. A complete monitoring scheme can provide basic data for implementation of tunnel support and check whether the new measure is effective. The section at Chainage $\mathrm{km} 235+495$ of the right tunnel was arranged as the monitoring station. The monitoring data include first contact stress (FCS) between surrounding rock and rigid support, second contact stress (SCS) between primary support and permanent lining through seven earth pressure cells, and surface displacement (SD) of surrounding rock. Attitude of strata and seven monitoring points are shown in Figure 15.

5.2. Surface Displacements. A total of 78 days were measured until the permanent lining being constructed. Among them, there is a period of downtime for 30 days. The monitoring results of seven points are shown in Figure 16. The total convergence deformation of surrounding rocks decreased significantly under the control of new yielding support with constant resistance. The deformations of all monitoring points were within $100 \mathrm{~mm}$ after the surrounding rock being stable. It means that this new support measure can effectively control large deformation of surrounding rock in the Minxian tunnel. The maximum deformation appeared at the right shoulder since the angle between the CRLD anchor cable and strata inclination was smallest. On the contrary, almost minimum deformation occurred at the left shoulder due to the larger angle and flexural rigidity. The excavation of three steps and bottom arch has a great influence on deformation of surrounding rock, which resulted in the deformation rate reaching $6-20 \mathrm{~mm} / \mathrm{d}$ because every construction behavior will cause certain disturbance to the surrounding rock and break the existing balanced state.

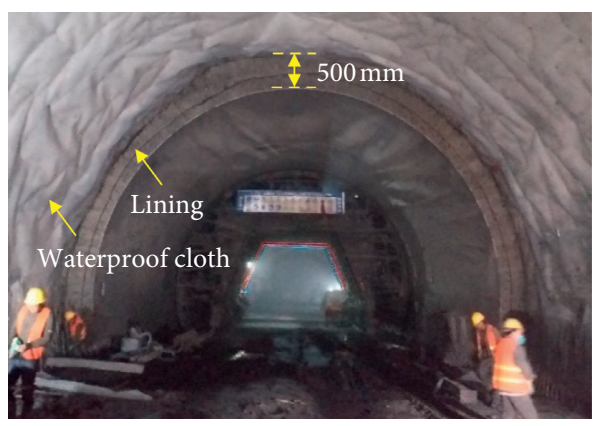

(a)

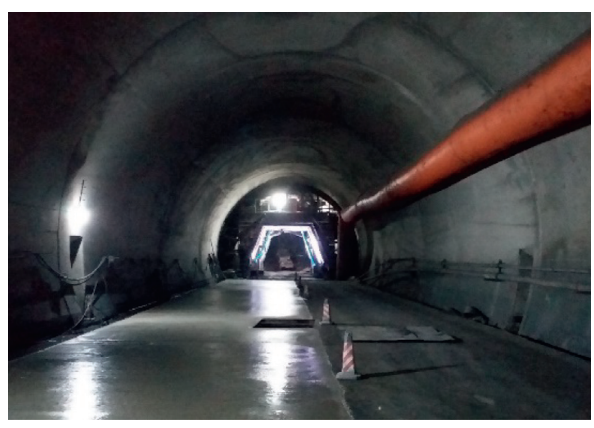

(b)

FIgURe 14: Permanent lining. (a) $50 \mathrm{~cm}$ reinforced concrete lining. (b) Finished tunnel.

After removing the impact of downtime, it can be estimated that the surrounding rock was in a period of rapid deformation within 20 days after the construction of primary supports (no permanent lining). The average movement rate of surrounding rock was $5-10 \mathrm{~mm} / \mathrm{d}$. The surrounding rock was in a period of slow deformation in range of 20-35 days, and the average deformation rate of surrounding rock was $3-5 \mathrm{~mm} / \mathrm{d}$. The deformation of surrounding rock tends to be stable after 35 days, corresponding to $40 \mathrm{~m}$ delay distance between the monitoring section and the tunnel face.

5.3. First Contact Stresses. In order to understand support effect of the new measures better, comparison of FCS monitoring curves under two support methods was conducted (Figure 17). It is noted that the monitoring curve of the original support was provided by the project department [17]. The maximum FCS appeared at the right shoulder of the tunnel using the original support method, and its value was $0.303 \mathrm{MPa}$ because this position had the maximum deformation of surrounding rock due to bending of layered strata. However, under the opposite dip direction of strata, the maximum FCS also occurred at the right shoulder of the tunnel using the new support system, and its value was $0.255 \mathrm{MPa}$ since this position had the maximum deformation of surrounding rock due to interlayer sliding. As mentioned in Section 5.2, the anchor effect was influenced by the angle between CRLD anchor cable and strata inclination. Compared with the original support, the maximum FCS of new support was reduced by $16 \%$. The distribution law of FCSes was consistent with deformation of 


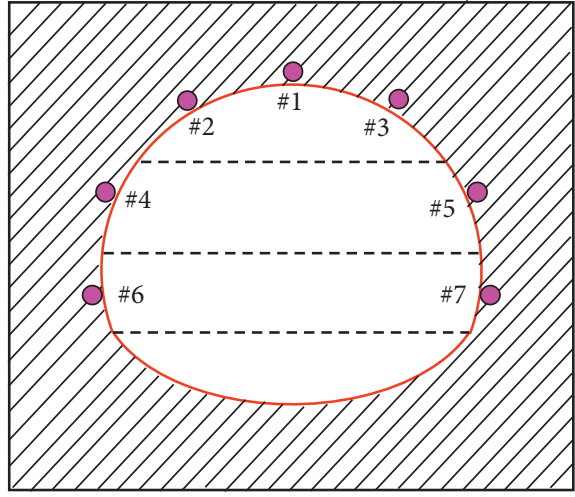

(a)

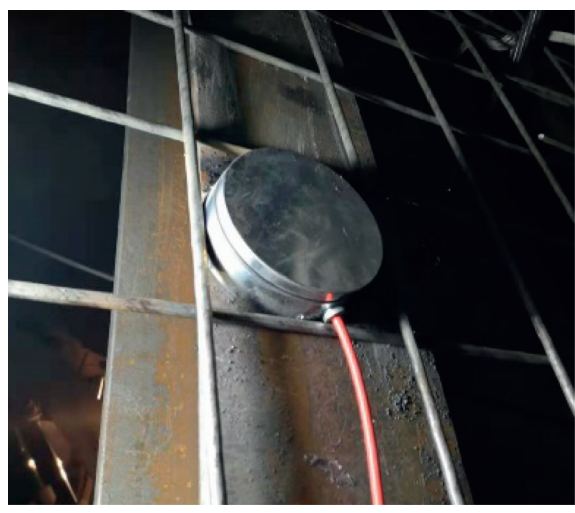

(c)

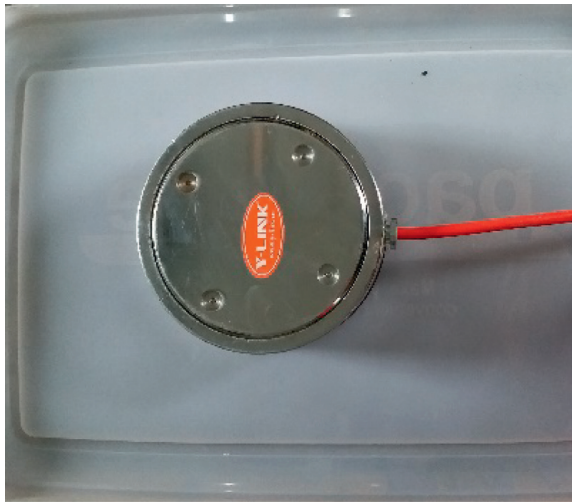

(b)

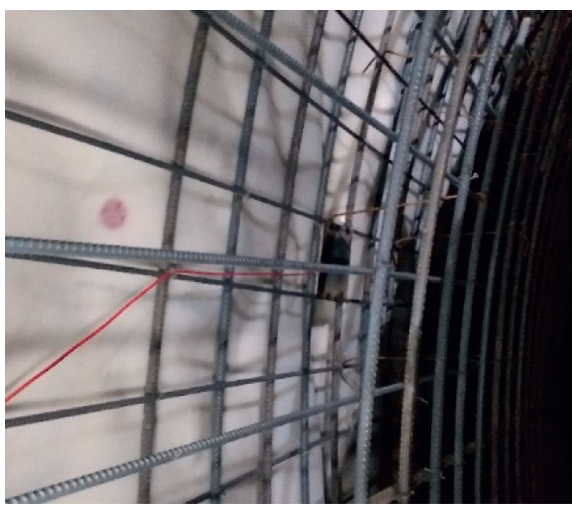

(d)

FIGURE 15: Monitoring scheme of the new support technology. (a) Monitoring section ( $\mathrm{km} 235+495)$ and points. (b) An earth pressure cell. (c) Installation of the first contact stress sensor. (d) Installation of the second contact stress sensor.

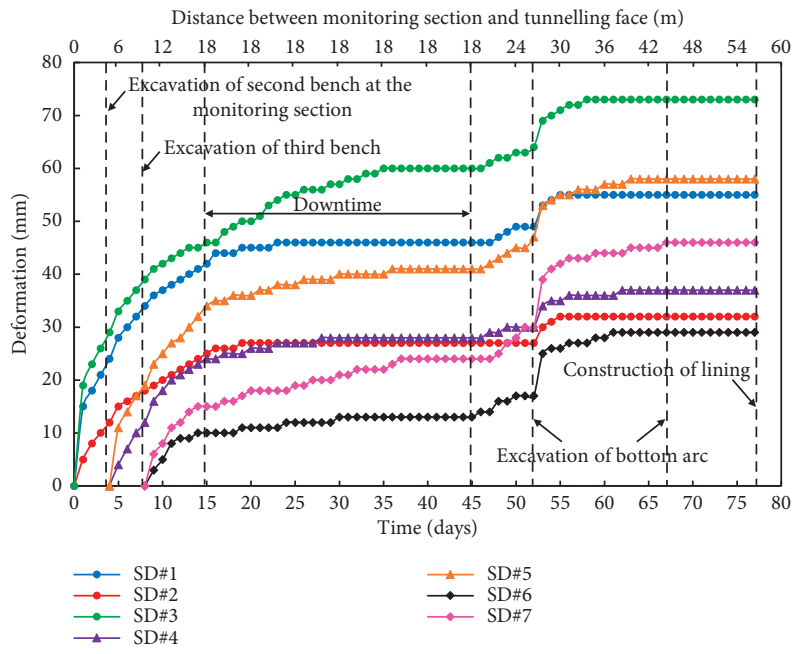

FIGURE 16: Monitoring curves of surface displacements vs. times using new support technology.

surrounding rocks, that is, larger surrounding rock deformation, greater FCS. Stress was more easily disturbed by various construction behaviors. Thus, the stability time of FCSes was longer than surrounding rock deformation. It took 141 days for the stabilization of the maximum FCS.
5.4. Second Contact Stresses. The monitoring curves of SCSes using original and new support methods are shown in Figure 18. It is noted that the monitoring curve of original support was provided by the project department [17].

The current maximum SCS using original support measure was $0.239 \mathrm{MPa}$, and the value was still unstable. According to the development trend of curves (Figure 18(a)), it can be estimated that the stabilized maximum SCS will appear at the right shoulder of the tunnel. The stabilized maximum SCS using the new support method occurred at right sidewall, and its value was $0.226 \mathrm{MPa}$. The SCSes reduced greatly after using new support technologies.

The SCSes increased rapidly in the early stage (0-10 days) after casting concrete due to the influence of hydration heat. Since the concrete at bottom of the lining was denser than at the top, there was bigger hydration thermal stress at bottom of the lining. Therefore, the SCS of the vault was smaller than other points although its deformation and FCS were greater. Different construction behavior had different effects on SCSes. When the working jumbo for the lining pouring was removed, the SCSes decreased suddenly due to the unloading effect. However, excavation of bottom inverted arch and construction of the next lining resulted in increasing SCSes. When the distance between monitoring station and tunnel face was more than 128-140 m, the SCSes 


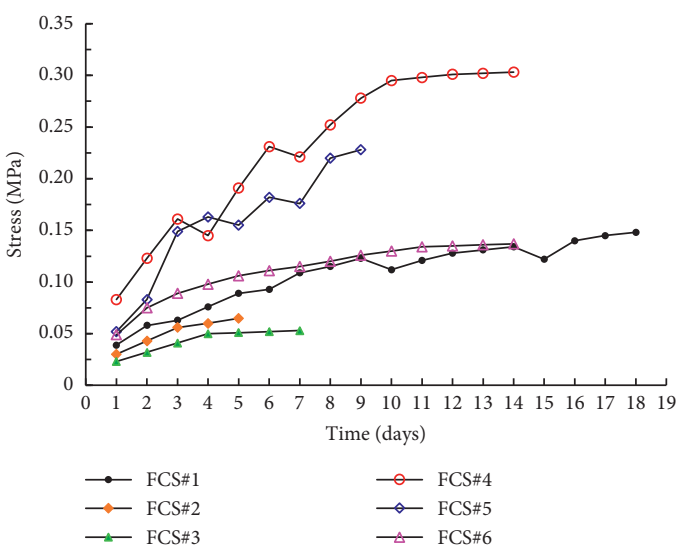

(a)

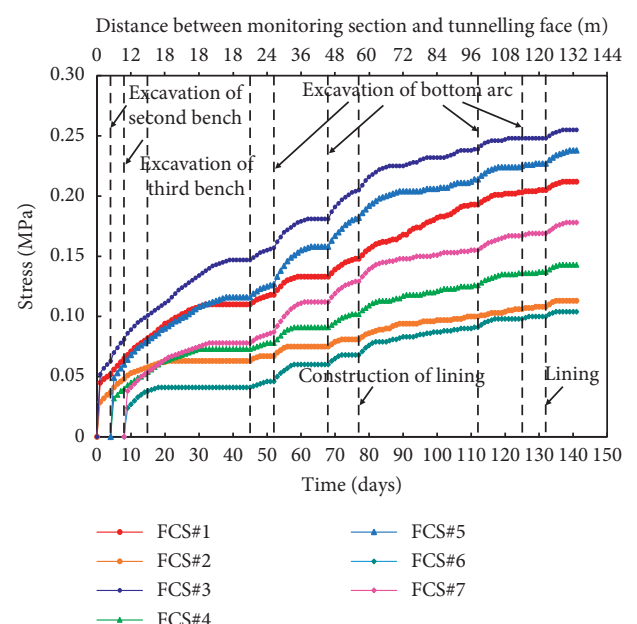

(b)

Figure 17: Monitoring curves of FCSes vs. times using (a) original and (b) new support technologies.

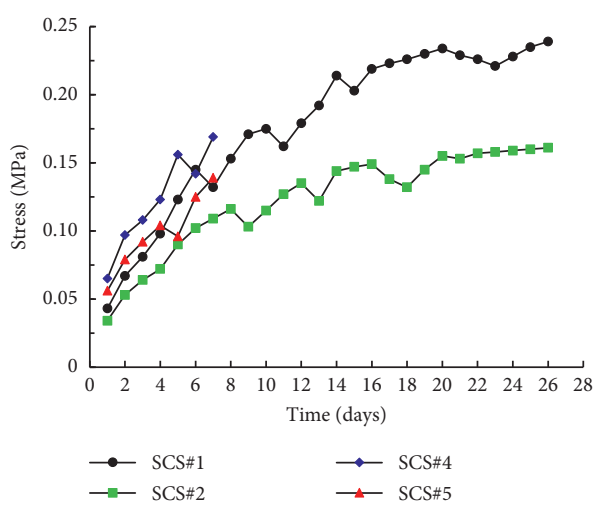

(a)

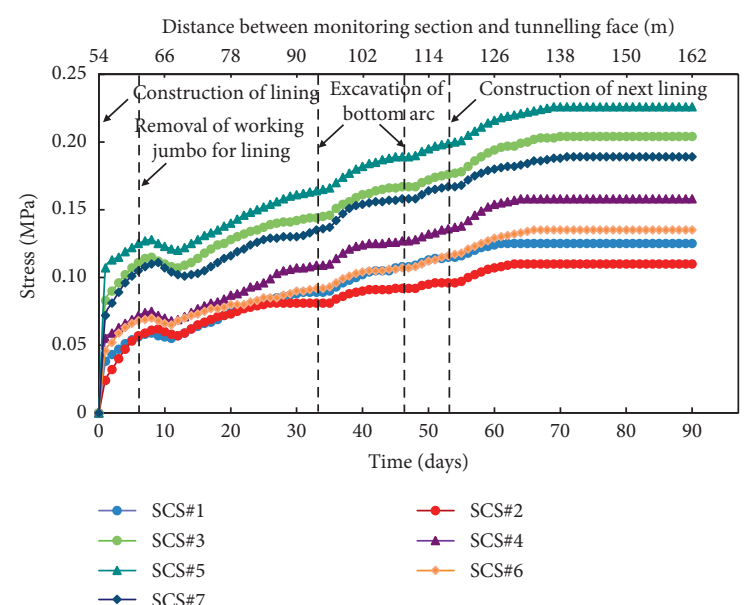

(b)

Figure 18: Monitoring curves of SCSes vs. times using (a) original and (b) new support technologies.

tended to be stable gradually, corresponding to $60-70$ days after the lining being poured.

\section{Conclusions}

In this paper, a case study on control measures of large deformation in the Minxian tunnel was introduced and the following conclusions can be drawn:

(1) Through laboratory analysis of mineral composition and field investigation on deformation characteristics of surrounding rocks, the large deformation mechanism of surrounding rocks of the Minxian tunnel was considered as molecules water-absorbing swelling of carbonaceous slate and stress-induced asymmetric structural deformations of surrounding rocks
(2) The new constant resistance and yielding support countermeasures were proposed and applied in the tunnel field. The technologies included front canopy, quickly spraying concrete, short and long constantresistance and large deformation (CRLD) anchor cables, preset deformation, I20a steel frames, and permanent lining.

(3) Filed monitoring results showed that the stabilized maximum deformation of surrounding rock was very small $(73 \mathrm{~mm})$ after using new support measures. The deformation of surrounding rock tended to be stable after 35 days, corresponding to $40 \mathrm{~m}$ delay distance between the monitoring cross section and the tunnel face. It was proved that large deformations of surrounding rocks in the Minxian tunnel could be effectively controlled, which can provide a reference for similar future projects. 


\section{Data Availability}

The data used to support the finding of this study are available from the corresponding author upon request.

\section{Conflicts of Interest}

The authors declare that they have no conflicts of interest.

\section{Acknowledgments}

The authors thank Fifth Engineering Co. Ltd. of First Highway Group of China Communications Construction for cooperation in the field tests and data collection for this study. The authors also gratefully acknowledge the financial support provided by the Gansu Changda Highway Co. Ltd.

\section{References}

[1] J. J. Chen and Z. G. Yan, "Rapid construction technology of zhongnan mountain extra-long tunnel in qinling mountains," Tunnel Construction, vol. 25, no. 1, pp. 41-44, 2005.

[2] G. L. Li and Y. Q. Zhu, "Control technology for large deformation of high land stressed weak rock in Wushaoling tunnel," Journal of Railway Engineering Society, vol. 3, pp. 54-59, 2008.

[3] G. Liu, "Study of support measures for large deformed section of Muzhailing tunnel in soft rocks," Model Tunnel Technology, vol. 48, no. 4, pp. 135-141, 2011.

[4] J. Lai, X. Wang, J. Qiu, Z. Chen, Z. Hu, and H. Wang, "Extreme deformation characteristics and countermeasures for a tunnel in difficult grounds in southern Shaanxi, China," Environmental Earth Science, vol. 77, no. 19, pp. 23-28, 2018.

[5] Z. Chen, C. He, G. Xu, G. Ma, and D. Wu, "A case study on the asymmetric deformation characteristics and mechanical behavior of deep-buried tunnel in phyllite," Rock Mechanics and Rock Engineering, vol. 52, no. 11, pp. 4527-4545, 2019.

[6] C. Zhang, X.-T. Feng, and H. Zhou, "Estimation of in situ stress along deep tunnels buried in complex geological conditions," International Journal of Rock Mechanics and Mining Sciences, vol. 52, no. 6, pp. 139-162, 2012.

[7] S. Wang, C. Li, Z. Liu, and J. Fang, "Optimization of construction scheme and supporting technology for HJS soft rock tunnel," International Journal of Mining Science and Technology, vol. 24, no. 6, pp. 847-852, 2014.

[8] Z. Zhang, X. Shi, B. Wang, and H. Li, "Stability of NATM tunnel faces in soft surrounding rocks," Computers and Geotechnics, vol. 96, pp. 90-102, 2018.

[9] F. Kimura, N. Okabayashi, and T. Kawamoto, "Tunnelling through squeezing rock in two large fault zones of the Enasan tunnel II," Rock Mechanics and Rock Engineering, vol. 20, no. 3, pp. 151-166, 1987.

[10] Z. D. Zhang and J. C. Bai, "Countermeasures of high gas content, large deformation and water gushing in Jiazhujing tunnel," World Tunnel, no. 1, pp. 1-10, 1998.

[11] E. Hoek and R. Guevara, "Overcoming squeezing in the yacambú-quibor tunnel, Venezuela," Rock Mechanics and Rock Engineering, vol. 42, no. 2, pp. 389-418, 2009.

[12] G.-H. Zhang, Y.-Y. Jiao, and H. Wang, "Outstanding issues in excavation of deep and long rock tunnels: a case study," Canadian Geotechnical Journal, vol. 51, no. 9, pp. 984-994, 2014.
[13] X. Ding, Y. Weng, Y. Zhang et al., "Stability of large parallel tunnels excavated in weak rocks: a case study," Rock Mechanics and Rock Engineering, vol. 50, no. 9, pp. 2443-2464, 2017.

[14] C. Cao, C. Shi, M. Lei, W. Yang, and J. Liu, "Squeezing failure of tunnels: a case study," Tunnelling and Underground Space Technology, vol. 77, pp. 188-203, 2018.

[15] M. C. He, H. H. Jing, and X. M. Sun, Theory of Soft Rock Engineering Mechanics, Science Press, Beijing, China, 2002.

[16] M. He, W. Gong, J. Wang et al., "Development of a novel energy-absorbing bolt with extraordinarily large elongation and constant resistance," International Journal of Rock Mechanics and Mining Sciences, vol. 67, pp. 29-42, 2014.

[17] W. Z. Chen, H. M. Tian, X. J. Tan, J. Q. Yuan, C. Rong, and Q. Sui, "Analysis on the mechanism of large deformation of layered soft rock and the lining failure of minxian tunnel in weiyuan-wudu expressway," Research Report, Institute of Rock and Soil Mechanics, Chinese Academy of Sciences, Beijing, China, 2018. 